\title{
O terceiro setor como mercado profissional
}

\author{
The third sector as labor market
}

\author{
Lúcia Helena Alves Muller \\ Marcia Cristina Alves \\ Décio Soares Vicente \\ Pablo de Oliveira Gonçalves*
}

\begin{abstract}
Resumo: Este texto apresenta uma análise das ofertas de vagas de trabalho em organizações reconhecidas como pertencentes ao terceiro setor. Esse perfil foi desenhado a partir da leitura de anúncios divulgados através de sites de organizações que são referência no âmbito desse campo social (Rits e Gife), entre os anos 2004 e 2006. O perfil desse novo espaço de trabalho constitui, também, um canal de observação que permite a reflexão acerca da configuração do campo das políticas sociais brasileiras.
\end{abstract}

Palavras-chave: Mercado de trabalho; Terceiro setor; Sociedade civil; Políticas públicas

Abstract: This article presents an analysis of job offers in organizations recognized as belonging to the third sector. This profile was developed based on the job offers published on the websites of organizations that are references in this social area (Rits and Gife) between the years 2004 and 2006. The profile of this new labor space also constitutes an observation channel that allows the reflection about the configuration of Brazilian public policies.

Key words: Labor market; Third sector; Civil society; Public policies

* Doutora em Antropologia Social (UnB), professora do PG em Ciências Sociais da Pucrs, Porto Alegre, Brasil.<lucia.helena@pucrs.br>; Marcia Cristina Alves, Pablo de Oliveira Gonçalves são graduados em Ciências Sociais e Décio Soares Vicente é mestrando em Ciências Sociais; participaram da pesquisa como bolsistas de iniciação científica (Fapergs e Pucrs). O texto é resultado de pesquisa realizada no Núcleo de Estudos de Empresas e Organizações (Neeo), vinculado ao PG em Ciências Sociais da Pucrs. Além dos autores citados o projeto contou com a colaboração de Paulo Ribeiro, como consultor em informática, e dos estudantes de graduação Murilo Cabral Nunes e Filipe Pasquotto Soares.

\begin{tabular}{|l|l|l|l|l|l|}
\hline Civitas & Porto Alegre & v. 9 & n. 2 & p. 281-306 & maio-ago. 2009 \\
\hline
\end{tabular}




\title{
Introdução
}

\begin{abstract}
Monitoramento pedagógico e avaliação de impacto
Organização do terceiro setor está selecionando profissional para atuar no monitoramento pedagógico e na avaliação de impacto. Os candidatos devem ter formação em pedagogia, ciências sociais ou áreas afins e larga experiência no terceiro setor. O profissional selecionado será responsável pela coordenação dos gerentes de monitoramento pedagógico, avaliação do programa, contato com instituições parceiras, elaboração e avaliação das publicações científicas, representação da organização em eventos diversos e análise quantitativa de dados de sistema de avaliação educacional em larga escala. É desejável conhecimento dos sistemas de avaliação SPSSwin, Bilog 3, Bilog-MG, Testfact, Microfact e Microcat, SAS e Parscale.
\end{abstract}

\section{(...) gerente do programa de política de comunicação e informação}

A (...) está contratando gerente para seu programa de política de comunicação e informação. A pessoa poderá trabalhar via internet. A pessoa selecionada será responsável por dirigir e desenvolver atividades cujo objetivo seja estimular a participação da sociedade civil em processos de decisão por meio de tecnologias de informação e comunicação (TICs).

O perfil desejado para ocupar a gerência é de alguém com experiência e conhecimento de políticas de uso de TICs em prol do desenvolvimento social. A entidade pede também que a pessoa já tenha trabalhado em redes da sociedade civil por pelo menos três anos e cinco em elaboração de projetos. É preciso, ainda, ter inglês fluente e desejável conhecimento de espanhol e francês. ${ }^{1}$

Para um pesquisador das ciências sociais que esteja atento ao mercado de trabalho, o surgimento do campo social que está sendo denominado de terceiro setor apresenta novidades muito interessantes. Quem tem algum contato com o universo das políticas públicas, com o mundo das fundações e institutos empresariais, das organizações não governamentais, dos projetos sociais, vai deparar-se com trajetórias e inserções profissionais incomuns em outros espaços sociais, como a de engenheiros e de biólogos que assumem a responsabilidade por políticas de relacionamento da empresa com a comunidade; de mecânicos que procuraram uma formação na área do serviço social para atuar no campo da filantropia empresarial; de economistas, professores de educação física, médicos e profissionais de relações públicas que produzem dissertações

Textos de anúncios de oportunidades de trabalho recolhidos na internet. Optamos por não identificar as organizações que os divulgaram. 
voltadas para a análise de temáticas relacionadas com a ação social; de cientistas sociais que buscam qualificação na área da administração; de psicólogos que atuam como consultores em projetos ambientais; de contadores, jornalistas, advogados, licenciados em história ou filosofia que buscam capacitação em cursos de formação em políticas públicas ou em gestão e avaliação de projetos sociais.

Quem acessar os sites das organizações que fazem parte do chamado terceiro setor, vai se deparar com uma grande quantidade de anúncios que demandam por profissionais com formação superior, não importando a área (do marketing às ciências sociais; da pedagogia à medicina; da administração à ecologia), desde que tenham experiência no uso de metodologias tais como a de elaboração e monitoramento de projetos sociais, captação de recursos, gestão de parcerias, além, é claro, do domínio das ferramentas da informática e, no mínimo, o domínio da língua inglesa (eventualmente, um outro idioma estrangeiro também é exigido).

Essa demanda vem acompanhada de uma oferta crescente de cursos em diversas modalidades - pós-graduação, treinamentos, programas de ensino à distância - voltados todos para a formação de profissionais capacitados para atuarem na área social. Associada a esses cursos, uma bibliografia cada vez mais abundante, composta por teses, estudos, análises e reflexões sobre o campo da ação social, assim como por manuais e guias que ensinam o uso de ferramentas úteis para a atuação profissional nesse campo de ação.

Podemos entender o caráter dessa demanda e das possibilidades de qualificação profissionais que vêm se apresentando nesse novo espaço social como produtos do processo de reestruturação e flexibilização dos mercados e da tendência a não-especialização do trabalho, que predominam na atual configuração do capitalismo. Mas elas refletem, também, mudanças que ocorreram em outras dimensões da vida social, pois dizem respeito ao surgimento de novas formas de organização das políticas públicas e dos reflexos desse novo modelo na configuração de um mercado de trabalho com características específicas.

Para abordar algumas dessas questões, esse trabalho propõe discutir, primeiramente, a possibilidade de se definir o chamado terceiro setor como um novo campo social. A seguir, faremos uma apresentação dos resultados da pesquisa sobre o mercado de trabalho formado por esse novo campo, e uma reflexão sobre o que esses dados podem revelar acerca da configuração das organizações que atuam no campo das políticas sociais brasileiras. 


\section{A formação de um novo campo social}

Ao longo das duas últimas décadas, a cada dia, um número crescente de organizações, grupos e indivíduos, de investimentos, mobilizações (eventos, redes), ações e expressões (publicidade, campanhas, discursos) se apresentam no espaço público reivindicando e sendo reconhecidos como integrantes do terceiro setor. Esse fato constitui, por si só, um fenômeno social, político, organizacional e ideológico digno de estudos (Fernandes, 1994; Ioschpe, 1997).

Mas apesar da grande visibilidade obtida por organizações do chamado terceiro setor, trata-se de um espaço social de definição teórica muito problemática e de difícil caracterização empírica. Em primeiro lugar, em razão da heterogeneidade das organizações, ações e propostas que a ele se apresentam vinculadas. Em segundo, porque as fronteiras, os princípios e valores que regem e legitimam a existência desse espaço social são alvo de conflitos bastante complexos e de disputas muito acirradas (Bourdieu, 1989).

Como já foi desenvolvido em outro texto (Müller, 2006), estas disputas podem ser evidenciadas, por exemplo, no uso de diferentes expressões utilizadas para nomear e classificar as organizações e ações que o compõem: Organizações Não-Governamentais (ONGs), Organizações da Sociedade Civil de Caráter Público, Organizações Solidárias, Organizações Socialmente Responsáveis, Organizações Filantrópicas, Organizações Sem Fins Lucrativos, Organizações ou ações sustentáveis etc.

As disputas também podem ser percebidas pela variedade de associações e redes que vêm sendo criadas para agrupar os diferentes tipos de organização e de propostas de atuação que concorrem no interior desse espaço social. E o conteúdo dessas disputas transparece na diversidade de posicionamentos que essas organizações assumem em relação a problemáticas políticas e sociais mais amplas, tanto no que se refere a políticas governamentais ou relativas à legislação do setor, quanto em relação a pautas políticas e sociais definidas em nível internacional.

Além disso, nas disputas pela definição do que é o terceiro setor também participam grupos, organizações e redes de âmbito internacional e/ou transnacional, que se originaram em campos sociais já há muito consolidados: organismos de Estado, universidades, instituições religiosas, partidos políticos, sindicatos, instituições filantrópicas, movimentos sociais, associações de defesa do interesses de grupos específicos etc. Esses participantes tentam valorizar a sua inserção nesse novo espaço através da reconversão do capital acumulado 
nos campos sociais de origem: competências profissionais específicas, capital social, político, acadêmico, religioso. (Pereira Neto, 2001; Silveira, 2001).

Assim, a formação do chamado terceiro setor coloca em interseção campos sociais, organizações, redes, histórias institucionais, identidades profissionais, princípios, lógicas, códigos de conduta, competências e linguagens muito distintos e diversos (Silva, 1996). O encontro dessa diversidade produz incompreensões, contradições e conflitos, mas também articulações, que se dão através da construção de acordos, arranjos e compromissos, e da criação de novas configurações (Boltanski e Thévenot, 1991; Boltanski e Chiapello, 1999).

Todos esses processos têm implicações muito fortes na construção da identidade das organizações envolvidas e na manutenção de sua legitimidade frente à sociedade mais ampla. Eles afetam de forma direta a sua configuração interna: a definição das lógicas que organizam seu funcionamento; as formas de distribuição do poder; os códigos que regulam o recrutamento, o engajamento, a atuação e as relações entre os seus integrantes (funcionários, voluntários); as relações com os parceiros e concorrentes institucionais, com os financiadores e com os beneficiários das ações, além, é claro, da relação com esferas mais amplas da sociedade (estado, organizações internacionais, movimentos sociais etc.).

Por suas dimensões e peculiaridades, o espaço de trabalho que vem se formando nas organizações do chamado terceiro setor merece ser alvo de análise. Além disso, o estudo desse espaço social pode contribuir para a compreensão das formas como lutas políticas mais amplas estão sendo travadas em nossa sociedade.

\section{O estudo das ofertas de trabalho no terceiro setor: questões metodológicas}

Para realizar esse estudo, escolhemos duas organizações que podem ser consideradas como referências no campo do terceiro setor: o Gife Grupos de Institutos, Fundações e Empresas (www.gife.org.br); e a Rits Rede de Informações para o Terceiro Setor (www.rits.org.br). A coleta de informações sobre as ofertas de trabalho no terceiro setor foi realizada nos sites dessas organizações, que divulgam informações, ofertas de trabalho e oportunidades de qualificação fornecidas por diversas instituições nacionais e internacionais.

O levantamento dos dados foi efetuado semanalmente, sempre às quartasfeiras. As ofertas de trabalho divulgadas nesses dois meios de informação 
foram arquivadas e, posteriormente, transferidas para um banco de dados dinâmico, que permite recuperar informações detalhadas da instituição que oferece a vaga, do tipo de cargo a ser ocupado, da função a ser exercida, da qualificação necessária etc. ${ }^{2}$

Nesse texto serão analisados dados relativos ao período de março de 2004 a fevereiro de 2006. Durante esses dois anos foram identificados 1.097 anúncios de oportunidades de trabalho oferecidas por organizações que se reconhecem como pertencentes ao campo do terceiro setor. Desses, 630 anúncios foram coletados no período entre março de 2004 e fevereiro de 2005, e 467, entre março de 2005 e fevereiro de 2006.

Nesse trabalho, optou-se por apresentar a análise de apenas cinco das variáveis que foram trabalhadas na pesquisa - cargo, função, formação, exigência e experiência - por serem as que permitem uma avaliação do campo de trabalho delineado pelas ofertas recolhidas nos sites de organizações do terceiro setor em termos da qualificação e das competências exigidas dos candidatos a uma oportunidade de trabalho.

Qualificação e competência são conceitos importantes na área de recursos humanos, sendo utilizados principalmente para definir o grau de instrução, os conhecimentos e as habilidades exigidos do ser humano para o cumprimento de determinada função. O conteúdo desses conceitos mudou conforme o momento do desenvolvimento do capitalismo e com a dinâmica do mercado de trabalho (Educação \& Sociedade, 1998; Freidson, s. d.).

Deve-se destacar que os dados contidos nos anúncios que foram alvo desse estudo apresentavam características para as quais não havia categorias prontas que parecessem totalmente adequadas para a sua classificação. Em função disso, optou-se pela criação de novas categorias, a partir da sistematização da variedade apresentada pelos próprios dados. Embora bastante trabalhoso, esse percurso fez com que a análise permanecesse o mais aberta possível à percepção das novidades que os anúncios viessem a apresentar, evitando

2 O banco de dados foi construído no programa Access. Sua estrutura permite que cada um dos registros comporte o texto completo do anúncio que foi coletado na internet. Também há espaço para que as informações sejam desmembradas e codificadas conforme as seguintes categorias (as palavras grifadas são os termos utilizados no banco de dados ): Nome da instituição que propõe a oferta de trabalho; Endereço da instituição; Local em que se situa a instituição (cidade, estado, país); E-mail da instituição; Área de atuação ou temática na qual a instituição atua; Público-alvo das ações da instituição; Data de edição do anúncio; Cargo oferecido; Função a ser exercida pelo candidato; Área em que o candidato deverá atuar na instituição; Local em que o candidato deverá atuar (cidade, estado, país); Nível de escolarização exigido; Área(s) de formação exigida(s); Experiência(s) solicitada(s) pela instituição; Exigência(s) feita(s) aos candidatos; Número de vagas oferecidas; Salário; Moeda; Fonte - Site em que a oferta foi anunciada; E-mail indicado para contato; Texto Original do anúncio. 
submetê-los precocemente a categorias criadas a partir de outros contextos. Nesse sentido, a análise que apresentamos pode ajudar na identificação de algumas mudanças que estão ocorrendo no mercado de trabalho brasileiro, em função do tipo de ocupações, de qualificações e de competências que começam ser valorizadas a partir da estruturação do chamado terceiro setor como campo profissional.

A definição das categorias a serem utilizadas na análise teve como base a hipótese principal que orientou o estudo: a de que o chamado terceiro setor poderia ser visto como um campo social em formação, no interior do qual organizações, grupos e indivíduos estariam disputando pela definição dos princípios e valores dominantes, e, ainda, que muitos desses agentes estariam buscando valorizar o capital já acumulado no âmbito de outros campos sociais, embora também já fosse possível detectar a presença de princípios e valores constituídos a partir do novo campo social, isto é, do próprio terceiro setor. Essa hipótese de trabalho orientou a abordagem dos anúncios de oferta de trabalho no terceiro setor, fazendo com que o tipo de qualificação e de competências profissionais demandadas nos anúncios fosse interpretado também como expressão e como resultado das disputas ali travadas.

Também foi necessário levarmos em consideração que as organizações que buscam profissionais através dos anúncios analisados nesse estudo não apresentam necessariamente as características predominantes nas organizações de natureza empresarial, as quais definem a dinâmica geral do mercado de trabalho. No campo do terceiro setor, as organizações diferem muito em termos de sua natureza (confessionais, oriundas de movimentos sociais, filantrópicas tradicionais, vinculadas a organizações político-partidárias, estatais, de origem empresarial); em função da autodefinição de seu papel na sociedade, a qual define também a forma de sua atuação no espaço público (implementadoras de políticas públicas, prestadoras de serviços, militantes em prol de propostas políticas amplas e/ou de causas sociais específicas, agentes difusores do engajamento voluntário ou filantrópico, agentes do marketing institucional, agentes evangelizadores, representantes ou defensores de interesses comunitários etc.). As organizações do terceiro setor também se distinguem em função do porte, da forma e da complexidade de sua estrutura interna; da ideologia e/ou modelo que orienta a sua gestão (perfil empresarial, submetida a hierarquias de caráter tradicional, estruturas igualitárias, submetidas a padrões definidos por grupos que definem sua identidade em função de um enraizamento local, do pertencimento étnico, da inserção comunitária, de filiação religiosa etc.). 
Assim, mesmo não tendo sido possível elaborar uma caracterização sistemática das organizações do terceiro setor, o reconhecimento de sua heterogeneidade é condição necessária para a apreensão adequada das peculiaridades das ofertas de trabalho que transparecem no conteúdo dos anúncios analisados.

\section{"Oportunidades" no campo do terceiro setor}

Nesse item, apresentaremos os resultados referentes à análise das ofertas de trabalho, agrupadas segundo as cinco categorias que foram selecionadas para discussão neste texto. Para auxiliar na construção dos agrupamentos, recorremos a definições que estão disponíveis em publicações cuja função é difundir padrões no campo da gestão de recursos humanos (manuais). No nosso entender, os conteúdos dessas definições estariam em consonância com o sentido dominante no senso comum dos profissionais formuladores dos anúncios analisados, bem como de seus leitores.

Apresentaremos primeiro uma descrição das variáveis que compõem cada uma dessas categorias e, a seguir, uma análise dos dados relativos ao primeiro período (mar. 2004-fev. 2005) sob a forma de gráficos que apresentam a participação de cada variável no total de referências feitas a cada categoria presente nos anúncios coletados. Posteriormente, esses dados são comparados com os dados coletados no segundo período da pesquisa (mar. 2005-fev. 2006).

\section{Cargos}

Segundo Chiavenato (1997), essa categoria define a posição hierárquica e os níveis de responsabilidade em relação à prestação de serviços e ao tratamento de informações de interesse da organização. Segundo esse autor, nas organizações, os ocupantes de cargos se dividem nas atividades de dirigir, supervisionar e efetuar certas funções.

Nessa pesquisa, os dados relativos aos diferentes tipos de cargos referidos nos anúncios coletados foram classificados da seguinte forma:

a) Cargos diretivos - cargos superiores na hierarquia das organizações, como: diretor, gerente, gestor, superintendente, coordenador, oficial, supervisor, chefe, subdiretor.

b) Cargos intermediários - cargos relativos a atividades de supervisão, assessoria e apoio, como: assessor; assistente, assistente executivo, auditor interno, auxiliar, instrutor, secretário executivo; analista; controlador; 
c) Cargos operacionais - auxiliar; técnico; agente.

d) Cargos de treinamento - cargos destinados a indivíduos que estão em formação ou iniciando uma carreira profissional, tendo, em geral, um contrato com características diferenciadas e tempo delimitado: estagiário, bolsista, monitor e trainees;

e) Voluntários - trabalho sem remuneração;

f) Sem vínculo - anúncios que buscam profissionais para executarem atividades ou tarefas específicas, sem vínculo permanente com a organização: consultor, colaborador; divulgador, pesquisador;

g) Sem informação - não identificam um cargo específico para o profissional requerido.

O gráfico a seguir apresenta os dados relativos à distribuição dos cargos presentes nos anúncios de vagas para profissionais em organizações do campo do terceiro setor, coletados entre março de 2004 a fevereiro de 2005.

Gráfico 1: Distribuição da demanda por cargos - mar. 2004-mar. 2005

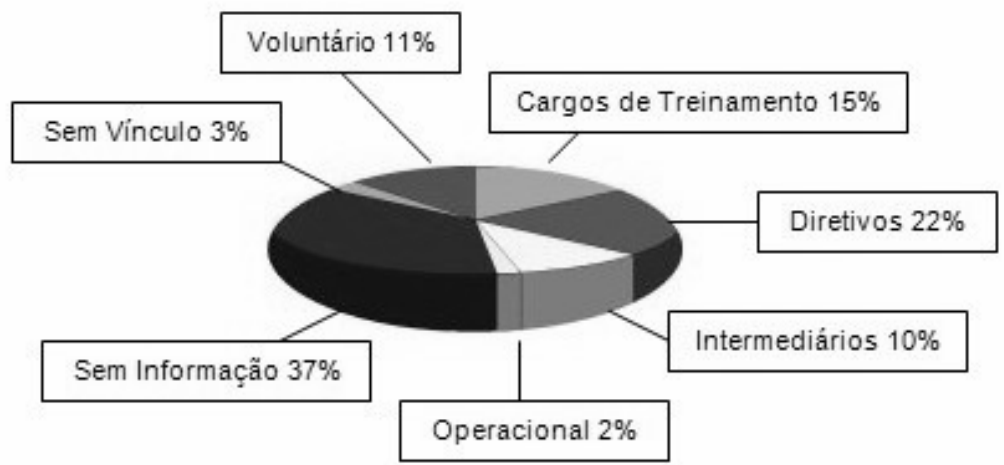

Fonte: Banco de Dados “Oportunidades”. Núcleo de Estudos de Empresas e Organizações Neeo-Pucrs.

Segundo o Gráfico 1, ainda que 37\% das ofertas de trabalho coletadas não especifiquem o cargo a ser ocupado na organização, $49 \%$ delas se referem a um cargo definido, sendo elevada a percentagem de ofertas de trabalho para cargos de Diretivos (22\%), isto é cargos que exigem alto nível de qualificação, tal como Gerente Sênior, Superintendente etc. Esses dados apontam para a existência de um grau relativamente elevado de estruturação e de hierarquização do trabalho nas organizações do campo do terceiro setor.

Por outro lado, a análise do gráfico também mostra que as organizações que conformam esse campo estão se tornando um importante espaço de 
formação profissional, na medida em que $15 \%$ das ofertas buscam candidatos para cargos de treinamento, como os de estagiários, trainees, bolsistas etc.

Os dados apresentados no Gráfico 1 também demonstram que, embora o trabalho voluntário seja muito valorizado, aparecendo em $11 \%$ das ofertas, as organizações que atuam neste novo campo social, marcado pela valorização das ações sem fins lucrativos e voltadas para as questões sociais, priorizam o recrutamento de profissionais assalariados ou de prestadores de serviços que, mesmo em caráter eventual, estabelecem vínculos contratuais com as organizações (consultores).

Os anúncios do período de 2005 a 2006 mostraram um crescimento significativo de ofertas de trabalho que especificam o cargo a ser ocupado ( $60 \%$ frente a $47 \%$ no período anterior). Essa diferença pode ser interpretada como sinal de um aumento no grau de profissionalização e hierarquização das organizações do terceiro setor.

Nos dados relativos ao período de 2005 a 2006 também houve um aumento de $5 \%$ no número de solicitações de candidatos para ocuparem cargos intermediários (relativos a atividades de assessoria e apoio).

\section{Função}

A variável função é definida por Chiavenato (1997) como um conjunto de tarefas ou de atribuições exercidas de maneira sistemática por um ocupante de cargo. Segundo esse autor, podemos também reconhecer as funções pelo próprio nome da profissão, como por exemplo, digitador: aquele que tem como função digitar.

Os dados relativos aos diferentes tipos de funções que, segundo os anúncios, deverão ser exercidas pelos candidatos a uma vaga de trabalho em organizações do terceiro setor foram classificados de acordo com as seguintes áreas:

a) Ambiental: acompanhamento a projetos agroecológicos, atividades na área de energias renováveis, manejo em reservas, desenho de mercado de produtos florestais, biólogo, coordenador de reposição florestal, especialista ambiental, especialista marinho, consultor de negócios sustentáveis, especialista de negócios em conservação, "carbono pecuarista", geógrafo etc.;

b) Cultura: artista, artista plástico, cinegrafista, coreógrafo, desenhista, professor de teatro, professor de dança, fotógrafo, oficina de arte e cidadania e artesão;

c) Saúde: médico, psicólogo, terapeuta ocupacional, enfermeiro, farmacêutico, obstetra, odontólogo, urologista, dermatologista, 
nutricionista, desenvolvimento de saúde pública, assessoria nacional de saúde, oficinas de saúde, ortodontia etc.;

d) Informática: arquitetura de design de website, assistente de informática, gerenciamento de informações; capacitador de grupos de inclusão digital, digitador, webdesigner, professor de informática, monitor de espaço na internet comunitária, programador de sistemas, assistente de suporte de rede, implantação e manutenção de sistemas, manutenção de computadores etc.;

e) Finanças: captação de recursos; analista de mercado; contador, auxiliar de contas a pagar, administrador financeiro, elaboração de orçamentos, pagamentos de contas, acompanhar fluxo de caixa, prestação de contas, assistente financeiro, gestão de recursos, lançamento contábil etc.;

f) Comunicação e publicidade: assistente de comunicação, assessor de imprensa, assistente de marketing, auxiliar nas estratégias de comunicação, campaigner, assessor de comunicação, produção de campanhas, clipagem de notícias, comunicação institucional, produção de release, produção de tv, coordenação de eventos, divulgador, editor de notícias, jornalista, publicitário, diagramador, redator etc.;

g) Educação e serviço social: residente social, genitor social, operador familiar, acompanhar e capacitar voluntários, agente educacional, capacitação de profissionais, desenvolver metodologias de ensino, oficineiro, assessor de direito da criança, assistente pedagógico, assistente social, educador, professor, monitor, palestrante, recreador, treinador, avaliador pedagógico, acompanhamento familiar, pedagogo, orientador educacional, palestrante, professor etc.;

h) Administração: administrador de recursos humanos, administrador, assistente técnico, análise de negociações comerciais, desenvolver projetos de estruturação da organização, gerenciamento de equipes, gerenciamento de materiais da instituição, negociação de contratos e serviços, secretaria executiva, planejamento estratégico, gerente administrativo sênior, gerente de recursos humanos, recepcionista etc.;

i) Gestão social: analista de gestão social, assessoria de programas, elaboração de projetos, avaliação de projetos, monitoramento de políticas públicas, mobilização comunitária, avaliação de impacto, mobilização de recursos, instrutor de oficinas, formação de lideres, fidelização de patrocinadores e doadores, negociação de parcerias, 
coordenador de voluntariado, consultor em responsabilidade corporativa, auxilio a produção de conteúdos locais, assessor de gênero, articulação de pessoas em rede, gestor de projetos, analista de investimento social, analista de projetos, acompanhar o trabalho de parceiros, analista em desenvolvimento, articulações com órgãos governamentais, assessor de captação de recursos, assessor de projetos, atuação em oficinas de ação comunitária, capacitação de agentes sociais, captar parceiros etc.;

j) Pesquisa: sociólogo, estatístico, assessor de pesquisa, coordenador científico, pesquisador, processamento de dados de pesquisa etc.;

k) Serviços gerais: auxiliar de serviços gerais, motorista, manutenção predial, marceneiro, mensageiro, atendente de lanchonete, eletricista, hidráulico, jardineiro, marceneiro, cozinheiro, serviços gerais, técnico de limpeza e conservação etc.;

1) Outros: este grupo contempla os dados presentes nos anúncios que não se enquadram em uma melhor conceituação: advogado, arquiteto, vendedor; tradutor, engenheiro etc.

m) Sem informação.

\section{Gráfico 2: Distribuição da demanda por função - mar. 2004-fev. 2005}

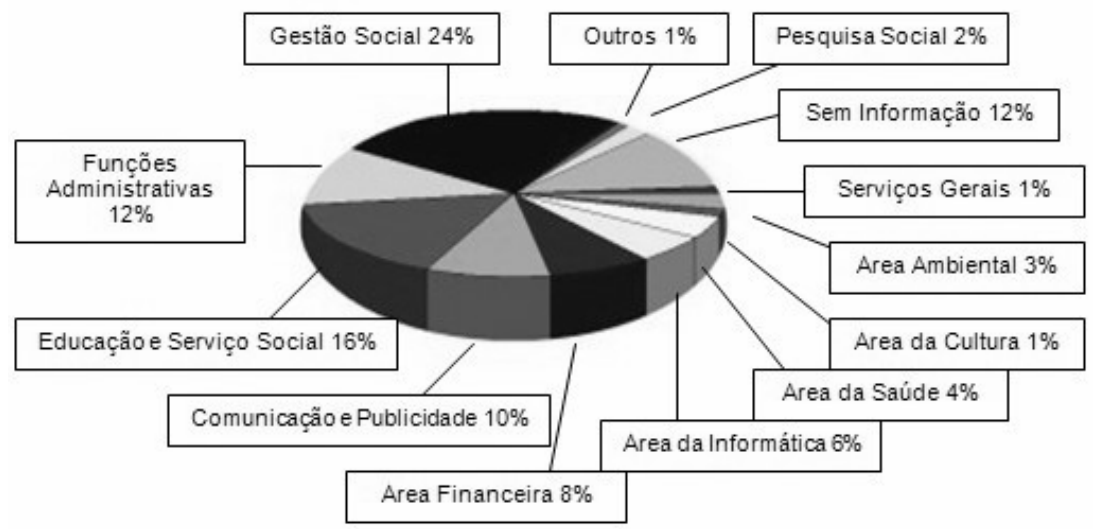

Fonte: Banco de Dados "Oportunidades". Núcleo de Estudos de Empresas e Organizações Neeo-Pucrs.

Os dados apresentados no Gráfico 2 sinalizam a complexificação interna das organizações do campo do terceiro setor. A partir dele também é possível verificar o predomínio de funções que poderiam ser consideradas como específicas ou típicas do terceiro setor. Elas estão agrupadas na categoria 
"gestão social", que representa $24 \%$ das funções identificadas nos anúncios, como por exemplo: analista de investimento social; analista de projetos, assessor de captação de recursos etc.

As referências relativas a funções classificadas pertencentes às áreas administrativa, da comunicação e publicidade, à área financeira, da pesquisa social e a de serviços gerais, somam 33\% dos dados representados nesse gráfico. Esse dado evidencia a existência de uma grande demanda por profissionais para desempenhar atividades-meio nas organizações do terceiro setor.

Por se tratar de um conjunto de atribuições e tarefas que muitas vezes se confundem com a definição de uma formação especializada ou profissão, a definição da função a ser exercida pelo candidato permite percebermos a existência de uma demanda por profissionais que atuam em áreas bem específicas, embora essas funções não constituam necessariamente setores autônomos dentro das organizações. Exemplo disso são as demandas para o desempenho de funções na área das finanças (contador, analista de mercado etc.) que reúne $8 \%$ das referências, e as da área da pesquisa (pesquisador, coordenador científico etc.), que somam $2 \%$ das referências, sem que as organizações possuam necessariamente um setor com essas designações. Um exemplo disso pode ser percebido no caso assistência social que, embora apareça como uma formação demandada (ver Gráfico 3), não aparece como constituindo uma área de atuação específica no interior das organizações que buscam profissionais no mercado. Essa aparente contradição pode ser melhor compreendida se levarmos em consideração o fato de que os valores e práticas comumente associados à idéia de trabalho assistencial tendem a ser considerados ilegítimos no interior do campo do terceiro setor, não se constituindo como referências adequadas e positivas, seja para a conformação de setores profissionais específicos, seja como esteio para a identidade pública das organizações.

Em relação ao ano anterior, pode-se notar, no período de 2005/2006, um crescimento significativo da participação da demanda por profissionais que deverão desempenhar funções administrativas (passou de $12 \%$ para $20 \%$ das demandas). Se somarmos a essas referências as demandas por profissionais que desempenharão funções da área financeira (9\%), chega-se a 29\% das funções referidas nos anúncios, participação que supera a das demandas para a área da educação e serviço social (15\%). Embora seja necessária uma avaliação mais precisa, pode-se pensar que, além da complexificação da estrutura das organizações, esses dados expressam o predomínio de uma percepção gerencial das organizações do chamado terceiro setor. 


\section{Formação profissional}

As informações referentes às exigências quanto à qualificação do candidato a uma vaga de trabalho em organizações do campo do terceiro setor contidas nos anúncios analisados, foram agrupadas nas seguintes categorias:

a) Área administrativa: administração de empresas, secretário executivo, economia doméstica, gestão de políticas públicas, recursos humanos etc.;

b) Área ambiental: administração rural, agronomia, biologia, desenvolvimento rural, ecologia, engenharia ambiental, engenharia de pesca, veterinária, zootecnia, oceanografia, preservação biológica, ecologia vegetal, gestão ambiental, preservação biológica, planejamento ambiental etc.;

c) Área da saúde: farmácia, ortondontia, saúde pública, psicologia, medicina, fonoaudiologia, ortodontia, enfermagem, terapia, nutrição etc.;

d) Área financeira: ciências contábeis e economia;

e) Arte e cultura: artes cênicas, artes plásticas, história da arte, educação artística, música, museologia, cinema etc.;

f) Ciências exatas: física, engenharia, engenharia de produção, estatística, matemática, química etc.;

g) Ciências humanas: sociologia, antropologia, ciências sociais, serviço social, ciências humanas, história, direito, relações internacionais etc.;

h) Comunicação e publicidade: comunicação e expressão, comunicação social, biblioteconomia, relações públicas, rádio, tv, jornalista, marketing, propaganda, publicidade etc.;

i) Educação: magistério, pedagogia, psicopedagogia, educação física etc.;

j) Informática: analista de sistema, ciência da computação, informática, programação de sistemas, sistema de informação, tecnologia da informação, webdesigner etc.;

k) Outros - este grupo contempla os dados que não se enquadram em nenhuma das categorias acima, como letras, língua brasileira de sinais, turismo;

1) Sem especificação: anúncios que não apresentam dados sobre o tipo de formação necessária para a vaga oferecida.

Os dados sobre a formação profissional demandada nos anúncios de trabalho no terceiro setor que foram recolhidos no primeiro período da pesquisa aparecem no Gráfico 3. 
Gráfico 3: Grupo por Formação - mar. 2004-fev. 2005

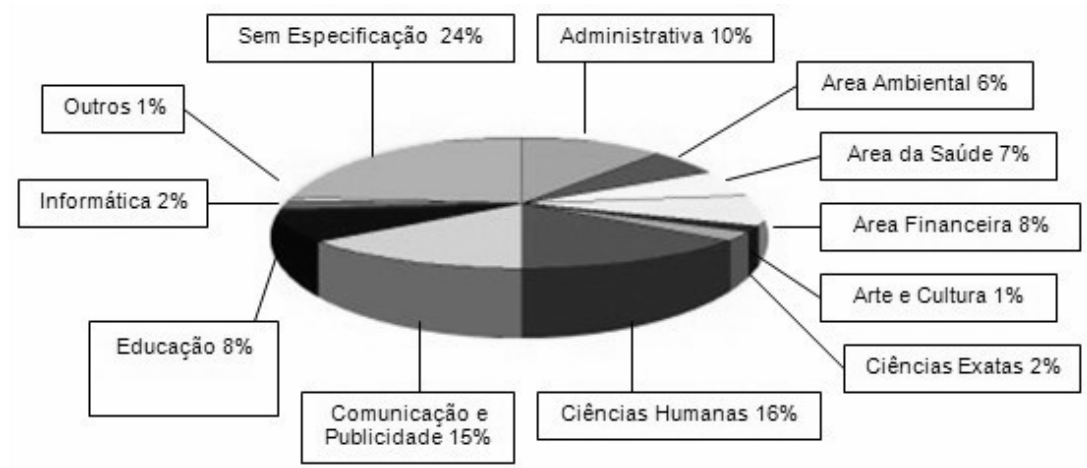

Fonte: Banco de Dados “Oportunidades”. Núcleo de Estudos de Empresas e Organizações Neeo-Pucrs.

No que se refere ao tipo e às áreas de formação profissional solicitadas, a característica mais marcante dos anúncios analisados é que eles apresentam mais de uma opção para a mesma vaga, sendo que as opções citadas nem sempre pertencem a mesma área do conhecimento. Além disso, uma parte significativa dos anúncios não especifica a área de formação exigida para os candidatos à vaga oferecida ( $24 \%$ das referências), apesar de muitos deles exigirem o domínio prático de certas ferramentas da informática, de determinadas técnicas de expressão (fotografia, cinema), ou de habilidades específicas (artesanato, música, esporte). Muitos anúncios solicitam que o candidato tenha experiência anterior em áreas de atuação como a de vendas, telemarketing, atendimento ao público etc., embora não especifiquem uma área de formação.

Como seria de se esperar, o Gráfico 3 mostra que a demanda por profissionais com formação em serviço social é significativa entre os anúncios que buscam profissionais para atuarem em organizações do terceiro setor. No entanto, esse tipo de formação divide o espaço da demanda com outras áreas das ciências humanas (ciências sociais, direito, história, relações internacionais) que, agrupadas, somam $16 \%$ das demandas de formação profissional especificadas nos anúncios.

Os profissionais formados nas áreas de comunicação e publicidade também têm boas possibilidades de serem contratados para atuar no terceiro setor: $15 \%$ das referências apresentam essas áreas como foco das ofertas de trabalho. A área administrativa aparece com 10\%, e a área financeira com $8 \%$. Podemos pensar que o fato dessas três áreas somadas representarem $33 \%$ das 
referências reforce a hipótese, já apontada por alguns pesquisadores (Steil, 2001; Tenório, 2004), de que o campo do terceiro setor esteja se conformando como um campo concorrencial, no qual as organizações têm que atuar de forma estratégica, mostrando-se eficientes na captação e gestão dos recursos e buscando reconhecimento e visibilidade frente à sociedade, para garantirem sua sobrevivência.

Pela leitura do Gráfico 3, também se pode depreender que os indivíduos que tiverem formação em áreas tradicionalmente voltadas para a temática social e ambiental encontrarão oportunidades de trabalho nas organizações do terceiros setor. A solicitação por profissionais formados na área da educação (pedagogia, magistério etc.) aparece em $8 \%$ das referências. Os que têm formação em disciplinas relacionadas com a promoção do desenvolvimento rural e com a área da preservação ambiental (agronomia, biologia, ecologia etc.) aparecem em 6\%. Os profissionais da área da saúde (medicina, nutrição, psicologia etc.) são alvo de 7\% das demandas, e os formados na área das artes (artes cênicas, música, artes plásticas etc.) aparecem em $1 \%$ das referências.

Profissionais com formação em áreas técnicas também são solicitados por organizações que compõem o campo do terceiro setor. Destacam-se os das áreas de informática e de ciências exatas (engenharia, estatística, desenho industrial etc.), cada uma delas com $2 \%$ das referências.

Comparados com os do ano anterior, os dados recolhidos entre março de 2005 e fevereiro de 2006, mostram que os anúncios que oferecem uma vaga de trabalho mas não especificam a área tipo de formação desejada tiveram um aumento de $13 \%$ (sua participação cresceu de $24 \%$ para $32 \%$ ). Esse dado está em consonância com a diminuição das referências a diversas áreas de formação (administrativa, da saúde, das artes e da cultura, das ciências exatas, informática, ciências humanas), que tiveram queda de $1 \%$ cada uma; e da área da educação, que teve queda de $2 \%$ em sua participação nas referências presentes nos anúncios.

Essas variações vão ao encontro da hipótese que orienta a pesquisa, que é a da ocorrência de um processo de autonomização do terceiro setor como campo social, na medida em que as organizações que o compõem estão sendo capazes de criar e difundir, elas próprias, as qualificações que responderão às suas necessidades, prescindindo, dessa forma, de profissionais que aportem uma formação escolar específica. A principal exigência passa a ser a apresentação de um grau mínimo de escolaridade (superior) que capacite o candidato a adquirir as qualificações necessárias através da prática profissional a ser vivenciada, inclusive no interior do próprio terceiro setor. Essa hipótese 
é reforçada pelos dados relativos às demandas por experiência que aparecem nos anúncios, os quais serão analisados a seguir.

Todos esses dados ganham mais sentido quando relacionados com aqueles referentes às exigências feitas aos candidatos, analisados mais adiante, pois grande parte dos anúncios demanda o domínio de conhecimentos e habilidades relacionados com atividades do campo das políticas sociais, bem como o domínio das chamadas "novas tecnologias sociais".

\section{Experiência}

Segundo Freidson (1996), a experiência profissional também faz parte do processo de qualificação; experiência no sentido de prática e/ou treinamento em alguma atividade profissional, não sendo necessário um conhecimento teórico considerável. A experiência faz parte do histórico do indivíduo, é o resultado de um convívio a priori com alguma atividade profissional.

Para esse autor, muitas das experiências adquiridas em algum ramo de atividade, pelo fato de não fazerem parte necessariamente de um processo de treinamento escolar, podem significar semiqualificações ou não-qualificações. $\mathrm{O}$ primeiro termo refere-se à atividade que requer prática e um rápido treinamento no próprio local de trabalho. O segundo faz parte das profissões sem instrução ou preparo suplementar, pois se baseiam apenas no conhecimento e na perícia cotidianos, no qual essas atividades são simples e repetitivas. Elas resultam em uma especialização mecânica.

Os dados relativos aos diferentes tipos de experiência anterior que os anúncios demandavam dos candidatos a uma vaga nas organizações do terceiro setor foram agrupados de acordo com as seguintes categorias:

A. Área ambiental: desenvolvimento de planos de ecossistemas, elaboração de diagnóstico ambiental, experiência em pesquisa de ecologia de fisiologia vegetal, gerenciamento de unidade de conservação, manejo florestal, sistemas agro-florestais, energia e clima, planos de preservação da biodiversidade, desenvolvimento sustentável etc.;

B. Arte e cultura: artes, cultura negra, folclore, dança, legislação cultural, percussão, artes gráficas, linguagem musical e circense, músicas regionais e populares, teatro, cultura popular etc.

C. Assistência social: abrigo para jovens, acompanhamento familiar, implantação de campanhas, atividades sociais, orientação familiar, trabalho social, trabalho com famílias, trabalho com jovens etc.; 
D. Atividades profissionais e técnicas: área administrativa, área comercial, experiência em gestão, experiência em lidar com equipes internas e de terceiros, experiência em vendas e/ou atendimento ao público, formação de lideranças, negociação, auditoria, contabilidade, e-commerce, exportação, planejamento, certificação, gestão de processos, recursos humanos etc.;

E. Domínio de novas tecnologias sociais: administração de ONGs, atuação em movimentos sociais, atuação no terceiro setor, captação de recursos, captação através de leis de incentivos culturais, convênios de cooperação técnica, coordenador de projetos, desenvolvimento de campanhas, elaboração de relatórios, formação de ONGs, gestão social, investimento social privado, planejamento participativo, projetos sociais, elaboração de projetos sociais, gestão de projetos sociais, responsabilidade social, voluntariado, economia solidária, gestão de parcerias, trabalho cooperativo etc.;

F. Educação: acompanhamento escolar, atividades socioeducativas, educação infantil, educação popular, formação de educadores, gestão educacional pública, educação complementar, orientação de jovens, educação não formal etc.;

G. Políticas públicas: administração pública, desenvolvimento de programas sociais, desenvolvimento local, lobby, marcos legais, medicina comunitária, orçamento público, participação em conselhos e fóruns, parcerias e convênios, direito da criança e do adolescente, relacionamento com as instituições da sociedade civil, relações com órgãos do governo etc.;

H. Públicos ou temas específicos: educação escolar indígena, HIV, proteção animal, saúde da mulher, trabalho comunitário, violência de gênero, inclusão digital, adolescentes, agricultura familiar, área ambiental, assentamento rural, associativismo produtivo, atuação em mídia jovem, colaboração em povos ou comunidades, criança da periferia, dependentes químicos etc.

I. Tempo: tempo de experiência profissional em uma determinada área de trabalho ou atividade, normalmente medida em numero de anos, que vão de 1 a 10 anos.

J. Sem informação. 
Gráfico 4: Grupo por Experiência - mar. 2004-fev. 2005

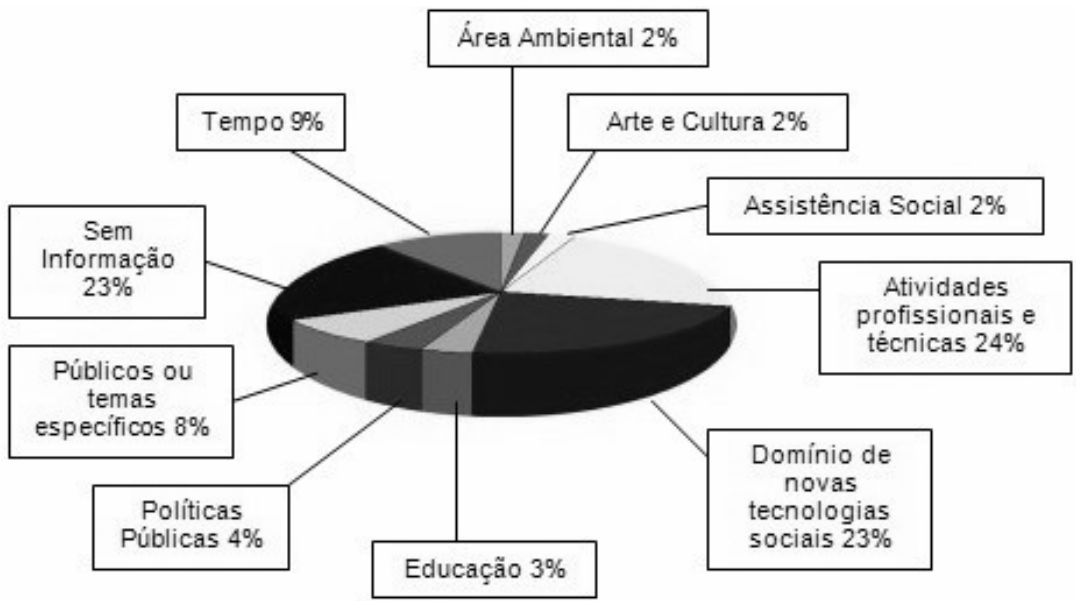

Fonte: Banco de Dados "Oportunidades". Núcleo de Estudos de Empresas e Organizações Neeo-Pucrs.

Os dados apresentados no Gráfico 4 evidenciam o tipo de experiência mais exigida para quem deseja trabalhar no campo do terceiro setor: as experiências que traduzem o domínio das chamadas "novas tecnologias sociais" como, por exemplo: experiência em elaboração de projetos sociais, em captação de recursos, em gestão social etc. A demanda por esse tipo de experiência soma $23 \%$ de todas as citadas nas ofertas de trabalho analisadas.

Considerando-se que as chamadas "novas tecnologia sociais" são modelos de compreensão da realidade e metodologias de ação que foram produzidos e/ou difundidos a partir das próprias organizações que compõem o campo do terceiro setor; e considerando, também, que domínio dessas "tecnologias" não faz parte, ainda, do conteúdo da formação escolar ou acadêmica regular, sua presença nos anúncios expressa a exigência de que os candidatos tenham uma vivência prévia em organizações que atuam no âmbito do próprio terceiro setor para estarem adequadamente qualificados para preencher uma vaga de trabalho nesse campo.

Outros dados que reforçam a hipótese de amadurecimento do terceiro setor como campo autônomo, dizem respeito às demandas que os anúncios apresentam em relação ao tempo de experiência que o candidato deve ter na área em que vai atuar. Entre os anúncios recolhidos, encontramos inclusive demandas que exigem de dois a dez anos de experiência de atuação no próprio terceiro setor. As demandas relativas a períodos mais longos de experiência 
são as que aparecem nos anúncios propostos por organizações que atuam na área ambiental, e por instituições internacionais.

Por outro lado, também é significativa a busca por profissionais com experiência em atividades de natureza administrativa (área comercial, financeira, de atendimento ao público), com experiência em atividades que envolvem o domínio da informática, em atividades das áreas da comunicação e da gestão da informação (gestão de banco de dados, bibliotecas). Esse tipo de atividade é citado em $24 \%$ das demandas por experiência que aparecem nos anúncios. Pode-se supor que a procura por profissionais experientes em gestão e administração expressa a necessidade das organizações em ocuparse com a sua própria estrutura e sua manutenção, do que com necessidades relativas às atividades por elas desenvolvidas junto ao público-alvo de suas ações sociais.

A análise dos dados contidos no Gráfico 4 permite constatar, ainda, que as organizações do terceiro setor também buscam por profissionais que já possuam uma trajetória voltada para as áreas tradicionalmente reconhecidas como de caráter social: educação (3\%), assistência social (2\%), área ambiental ( $2 \%$ ), arte e cultura (2\%). Somadas, essas áreas compõem $9 \%$ das referências que aparecem nos anúncios.

Os dados recolhidos no período 2005/2006 apontam para a tendência de amadurecimento do terceiro setor como campo profissional, na medida em que mostram o crescimento de $3 \%$ (de $9 \%$ para $12 \%$ ), no número de referências relativas à exigência de um tempo mínimo de experiência por parte dos candidatos a uma vaga.

Os dados desse período também revelam uma diminuição de 3\% na demanda por profissionais com experiência em políticas públicas (de 4\% para $1 \%)$, em relação ao ano anterior.

\section{Exigência}

Segundo Chiavenato (1997), as exigências podem ser definidas como um conjunto de atribuições ou características requisitadas por instituições na contratação de seu pessoal. As exigências podem se referir a características de qualificação e de competência pessoal, bem como socioculturais e políticoideológicas.

Qualificações são os conhecimentos que os profissionais possuem sobre determinada habilidade técnica ou método. As competências pessoais são aquelas aptidões subjetivas de cada indivíduo, como criatividade, inovação, talentos, virtude, facilidade com o trabalho em equipe, responsabilidade e capacidades "cognitivas" em compreender, antecipar e resolver problemas. 
Essas qualidades são inerentes ao indivíduo e não podem, muitas vezes, ser aprendidas em cursos ou treinamento, através de conteúdos programados, métodos e técnicas. Elas fazem parte da personalidade individual.

Manfredi (1998) indica que o conceito de competência veio no sentido de agregar um novo modelo de profissional, mais autônomo e preparado, com requisitos pessoais para lidar com situações novas. Segundo essa autora, as competências socioculturais fazem parte do universo social simbólico do profissional. Elas são dadas em um determinado tempo histórico, em uma determinada cultura em que ele foi socializado. Por fim, as competências político-ideológicas são aquelas associadas aos interesses e valores do indivíduo.

Vale lembrar que grande parte dos anúncios de ofertas de trabalho no campo do terceiro setor apresenta mais de uma exigência. Assim, não se pode utilizar como universo de referência todos os anúncios consultados, e sim todas as exigências citadas nos anúncios recolhidos. Organizados dessa forma, os dados expressam muito mais o perfil do profissional que é valorizado pelas organizações do campo do terceiro setor, do que a caracterização desse mercado de trabalho em termos quantitativos.

Os dados relativos às exigências demandadas para os candidatos a uma vaga no campo do terceiros setor foram agrupados de acordo com as seguintes categorias:

a) Qualificação técnica: capacidade de avaliação de relatórios, conhecimento de legislação tributária, carteira de habilitação, conhecimento de legislação trabalhista, conhecimentos em informática, elaboração de laudos técnicos, gestão da informação, noções de contabilidade, conhecimento de artesanato, estar cursando o penúltimo ano de administração, conhecimento avançado de excel, conhecimento de língua inglesa etc.;

b) Competência: boa articulação, boa comunicação, boa redação, bom humor, capacidade de gerenciamento de equipes, capacidade para tomar decisões, criatividade, espírito de solidariedade, capacidade de trabalhar sob pressão, persistência, rapidez e prontidão, senso estético, capacidade de relacionamento com área acadêmica, compromisso ético, perfil de animador, paciência, dinamismo etc.;

c) Disponibilidade: disponibilidade de horário, disponibilidade de residir em outra cidade, disponibilidade para viagens, flexibilidade de horários, trabalhar em casa etc.; 
d) Domínio de novas tecnologias sociais: domínio de conhecimentos e técnicas que estão sendo desenvolvidas no campo da ação social, como: inclusão digital, comunicação comunitária, conhecimento da realidade político-social brasileira, especialização em mobilização de recursos, especialização em terceiro setor, habilidades de interlocução com povos indígenas, conhecimento da Loas, conhecimento do terceiro setor, conhecimento em marketing social, especialização e mobilização de recursos, familiaridade em cidadania, técnico em construção de indicadores sociais, formação em políticas públicas etc.;

e) Motivação e interesses: afinidade com movimento social, compromisso com a mudança social, compromisso com a não violência, conhecimento e interesse pela área cultural, interesse pelo terceiro setor, interesse pela causa solidária, sensibilidade com questões de gênero, identificação com o princípio da desobediência civil, interesse em contribuir para mudança de comportamento do consumidor, sensibilidade social, interesse em artesanato de tradição e cultura, interesse pela realidade dos países africanos etc.;

f) Características pessoais: refere-se a características pessoais que facilitem ao candidato seu engajamento no trabalho ou permitam o estabelecimento de alguma identidade ou afinidade com o grupo que será alvo das ações sociais. por exemplo: ser afrodescendente, ser solteiro morar no local, não ter filhos menores dependentes, ter entre 20 e 30 anos, ser do sexo feminino, ser gay, ser lésbica, ser negro, ser portador de necessidades especiais, ser travesti, ter deficiência auditiva, morar e ter vínculo na baixada fluminense, ser jovem de baixa renda, ser divorciado etc.;

g) Nível de escolaridade: estar no segundo nível do curso superior; cursando, no máximo, o terceiro nível do curso; estar cursando a graduação; estar cursando entre o quarto e o sétimo semestre;

h) Outros: este grupo reúne dados relativos a exigências muito específicas, que não se enquadram em uma melhor conceituação. Algumas delas dizem respeito à posse dos meios necessários para a atividade a ser exercida, como: possuir consultório, possuir notebook, possuir veículo próprio, equipamento digital etc.;

i) Sem informação. 
Gráfico 5: Grupos por exigência - mar. 2004-fev. 2005

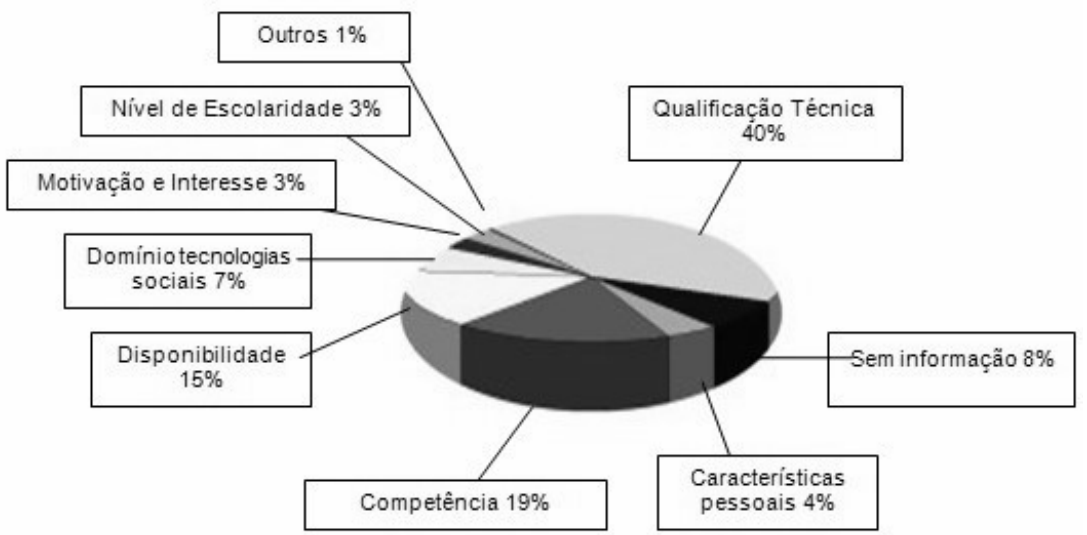

Fonte: Banco de Dados “Oportunidades”. Núcleo de Estudos de Empresas e Organizações Neeo-Pucrs.

Os dados organizados no Gráfico 5 mostram que os indivíduos que quiserem ingressar como profissionais no campo do terceiro setor devem apresentar alguns requisitos, em especial no que se refere à qualificação técnica, que aparece em $40 \%$ das ocorrências. Nessa categoria estão incluídas qualificações mais generalistas, como a de possuir conhecimentos na área da informática, o domínio de ferramentas de administração e finanças (gestão, contabilidade, vendas), domínio de idiomas estrangeiros, de algum tipo de legislação específica, de formação para o magistério etc. Mas também aparecem exigências de qualificações mais específicas, como dança, desenho, ou, ainda, algum tipo de especialização, como: conhecimentos na área da saúde reprodutiva ou sobre espécies marinhas. Isso demonstra que o campo do terceiro setor está se constituindo um espaço de trabalho muito diversificado e qualificado, para o qual podem dirigir-se profissionais com perfis e trajetórias muito variados.

Por outro lado, mesmo nos anúncios que buscam profissionais com qualificações tradicionais, já aparece a exigência de domínio das chamadas "novas tecnologias sociais", ou seja, das qualificações que podem ser consideradas típicas do "terceiro setor". Elas aparecem em 7\% das ocorrências.

No que se refere às exigências específicas, $19 \%$ das que aparecem nos anúncios conformam um perfil profissional com características e habilidades para adaptar-se a ocupações flexíveis e adaptáveis às demandas de um mercado 
de trabalho imprevisível. Para isso os candidatos devem ter a capacidade de gerenciamento, capacidade para identificar e analisar oportunidades, capacidade de liderar equipes, facilidade de negociação, iniciativa, comunicação etc. A presença dessas exigências demonstra que no âmbito do terceiro setor, o trabalho assume características muito similares às que definem o trabalho no âmbito das empresas que atuam sob o modelo de produção flexível.

Outros dados que chamam a atenção por apontarem para ocupações com características adequadas ao modelo de produção flexível são as exigências que aparecem nos anúncios, relativas à disponibilidade e flexibilidade em relação à jornada de trabalho e à mobilidade geográfica (15\% das referências). Entre os anúncios analisados, existem aqueles que exigem que o profissional trabalhe em seu próprio domicílio. Outros propõem contratos de trabalho temporário, trabalho na modalidade freelancer; há anúncios que propõem contrato de trabalho com horário reduzido, mas fixo; outros que demandam disponibilidade para cumprir jornadas que vão de poucas horas semanais até a dedicação exclusiva. Há anúncios que exigem disponibilidade para jornadas noturnas, para o trabalho em finais de semana; outros pedem disponibilidade para viagens, para mudanças de domicílio etc.

Muitos dos anúncios que demandam disponibilidade para poucas horas de trabalho semanais dizem respeito a vagas para trabalho voluntário ou para cargos de treinamento (estagiários, treinees). Conforme já foi demonstrado na análise dos dados relativos aos cargos, essas categorias perfazem, juntas, $26 \%$ dos anúncios recolhidos no primeiro período (2004/2005), e 30\% dos anúncios no segundo período (2005/2006). As vagas para treinamento também apresentam exigências quanto ao nível de escolaridade, uma vez que a grande maioria dos anúncios que faz esse tipo de exigência busca por estudantes, definindo apenas o número mínimo de anos de formação que o candidato deve ter no currículo; ou o número máximo, como acontece no caso dos estagiários, pois eles não devem ter concluído o curso de graduação.

Os dados do gráfico relativo às exigências apresentadas nos anúncios também trazem informações significativas para se avaliar o processo de formação do campo do terceiro setor. Essas informações estão contidas nos dados relativos às características, aos valores pessoais, aos interesses socioculturais e aos compromissos político-ideológicos exigidos dos indivíduos que desejam se candidatar às vagas oferecidas. É o que podemos perceber ao analisar, no gráfico acima, o dados que foram aglutinados pela categoria Motivação e interesses, que conta com $3 \%$ das referências. 
O que encontramos nesse grupo são exigências de afinidades, compromisso e/ou engajamento com as causas que são o objeto das organizações, ou com os princípios pelos quais elas pretendem pautar suas ações. Como exemplo, podemos citar: sensibilidade social; afinidades com o movimento social; compromisso com a mudança social; interesse por relações raciais; identificação com o princípio da desobediência civil; interesse pela realidade de países africanos; conhecimento e interesse na conservação do meio-ambiente; interesse pelo tema da Aids, pelo tema da infância etc.

Uma outra face desse fenômeno aparece nos registros de exigências relativas às características pessoais dos candidatos. Mais do que perfis adequados ao mercado de trabalho, o que se vê nesses dados é a exigência de que os candidatos se identifiquem (ou sejam identificados) com os grupos sociais ou causas que são o alvo das ações propostas pelas organizações. É isso que nos permite compreender a existência de anúncios de trabalho que demandam por candidatos que sejam gays, ou portadores de alguma deficiência, que sejam afrodescententes, que morem em regiões habitadas por populações carentes etc. Essas exigências, que representam $4 \%$ de todas as registradas no período de 2004-2005, podem indicar, por um lado, a busca pelo engajamento dos candidatos nas causas das organizações. Por outro, podem ser uma forma das organizações buscarem uma maior aproximação com as populações com as quais trabalham.

Nos anúncios recolhidos durante o período de 2005-2006 ocorreu um aumento de $5 \%$ (de $40 \%$ para $45 \%$ ) na demanda por qualificação técnica dos candidatos a uma vaga nas organizações do terceiro setor.

Por outro lado, houve uma queda de $3 \%$ (de 19\% para 16\%) em relação ao período anterior na presença de exigências relativas às competências pessoais que os candidatos devem apresentar.

\section{Notas finais}

Esse texto apresenta uma possibilidade de leitura de informações sobre oportunidades profissionais oferecidas, através da internet, por organizações que se identificam como pertencentes ao terceiro setor. Trata-se de uma análise descritiva que, focando apenas algumas das variáveis levantadas, buscou dialogar com a literatura sobre o mercado de trabalho e sobre a que trata da temática do terceiro setor, buscando levantar hipóteses acerca da formação de um novo espaço profissional e acerca da configuração de um novo campo social. 
Pela leitura realizada, foi possível perceber vários indícios da formação de um espaço profissional importante e peculiar, não apenas por sua dimensão numérica, mas, principalmente, pelas características que conformam o perfil dos profissionais demandados. Além disso, a análise dessas ofertas de trabalho demonstrou ser uma maneira eficaz de se identificar empiricamente as características que vem assumindo um espaço social cuja análise é essencial para se compreender a sociedade brasileira na atualidade: o chamado terceiro setor.

\section{Referências}

BOLTANSKI, Luc; CHIAPELLO, Ève. Le nouvel esprit du capitalisme. Paris: Gallimard, 1999.

BOLTANSKI, Luc; THÉVENOT, Laurent. De la justification: les économies de la grandeur. Paris: Gallimard, 1991.

BOURDIEU, Pierre. O poder simbólico. Lisboa: Difel, 1989.

CHIAVENATO, Idalberto. Recursos humanos. $4^{\mathrm{a}}$ ed. São Paulo: Atlas. 1997.

EDUCAÇÃO \& SOCIEDADE. Campinas: Cedes, v. 19, n. 64, set. 1998 [Competência, Qualificação e Trabalho].

FERNANDES, Ruben Cesar. Privado porém público: o terceiro setor na América Latina. Rio de Janeiro: Relume-Dumará, 1994.

FREIDSON, Eliot. Para uma análise comparada das profissões: a institucionalização do discurso do conhecimento formais. Revista Brasileira de Ciências Sociais, n. 31, 1996.

IOSCHPE, Evelyn B. (Org.). $3^{\circ}$ Setor: desenvolvimento social sustentado. São Paulo: Paz e Terra, 1997.

MANFREDI, Sílvia Maria. Trabalho, qualificação e competência profissional: das dimensões conceituais e politicas. Educação \& Sociedade: competência, qualificação e trabalho - revista quadrimestral de Ciências da Educação, n. 64, 1998.

MÜLLER, Lúcia H. A construção do social a partir da ótica empresarial. V Workshop Empresa, Empresários e Sociedade: o mundo empresarial e a questão social. Anais. Porto Alegre, Pucrs/FEE, 2006 (CD rom).

PEREIRA NETO, Francisco. Assistência social e caridade em Porto Alegre. I Seminário Organizações e Sociedade: perspectivas transdisciplinares. Porto Alegre, PPG Ciências Sociais - Pucrs, 2001.

SILVA, Márcia Terra. O processo de formação de culturas regionais: um estudo de caso sobre o metrô de São Paulo. In: FLEURY, Maria Tereza; FISCHER, Rosa Maria (Coord.) Cultura e poder nas organizações. São Paulo: Atlas, 1996.

SILVEIRA, Sérgio Skieresinski. A inserção do psicólogo no terceiro setor. Unisinos, 2001 (Trabalho de graduação - Mimeo). 